\title{
DE QUEM É O ESPAÇO ENTRE INSTITUIÇÕES?
}

Porfírio SILVA ${ }^{1}$

1. Parecerá absurda a pergunta: haverá teorias sobre a realidade que fazem de conta que o espaço não conta? Na verdade, absurdo mesmo é que a resposta seja positiva. Talvez não seja difícil imaginar que o exemplo vem da Economia. Vejamos.

Como teoria económica, o modelo neoclássico padrão, Walrasiano, que é um modelo de equilíbrio geral, baseia-se nas noções de mercado e sistema de preços: a oferta satisfaz a procura a um preço que é público; os mesmos bens e serviços (com as mesmas propriedades, fixadas antecipadamente) são negociados ao mesmo preço, sob as mesmas regras e virtualmente ao mesmo tempo; todos os agentes do mercado participam no processo e todos estão plena e igualmente informados sobre as mercadorias e sobre os termos da troca. Se as coisas se passassem assim, nenhum esforço seria necessário para efectuar trocas, excepto dispor da apropriada quantidade de dinheiro. Muitos autores têm notado que este modelo é profundamente irrealista, designadamente porque há trocas em contextos bilaterais (fora do mercado aberto), porque nem todos os participantes têm a mesma informação sobre as mercadorias em causa, porque a economia real envolve custos de transacção (mais sobre isto daqui a pouco).

Num plano mais geral, um forte elemento de irrealismo nesta economia ortodoxa é a obliteração do tempo: é como se toda a negociação para um conjunto de trocas de uma determinada mercadoria acontecesse ao mesmo tempo, por uma espécie de contrato de duração nula. O Prémio Nobel da Economia em 1993, Douglas North (1990: 30), fez precisamente esta crítica de irrealismo a esta ortodoxia económica, falando numa concepção em que as trocas aparecem como se fossem instantâneas. Mas acrescentou: é como se o mercado estivesse concentrado num único ponto do espaço.

Estamos a dizer que tais teorias negam a existência do tempo ou do espaço? Não; estamos a dizer que são teorias que atingiram um tal grau de formalismo que desconsideram o tempo e o espaço nos seus fundamentos. E esse formalismo, tão

Recebido: Março 2015. Aceite: Junho 2015.

1 Porfírio Silva, Filósofo das Ciências, é colaborador do Instituto de Sistemas e Robótica (Instituto Superior Técnico) e do Centro de Filosofia das Ciências da Universidade de Lisboa, onde desenvolve investigação sobre as sociedades artificiais e o papel social dos robots. Email: porfiriosilva@isr.ist.utl.pt 
profundamente enraizado num padrão de "cientificidade" dominante, precisa de recursos teóricos alternativos para ser combatido.

Uma das várias estratégias para combater este irrealismo assenta na ideia de custos de transacção. Quer dizer: nenhuma acção no mundo real acontece sem esforço. As mercadorias ou os factores de produção têm de ser levadas de um ponto para outro (não, não estão todos no mesmo ponto do espaço). Não há parceiros automáticos para as trocas: é preciso procurá-los, analisá-los, escolhê-los; é preciso monitorizar o cumprimento de um contrato. Há organizações - não apenas mercadorias e preços e trocas instantâneas - e as organizações podem ser mais ou menos bem geridas e têm custos. As regras que supostamente ordenam um mercado (ou qualquer outra arena da acção humana) nem sempre são cumpridas, nem sempre são sequer claras; podem surgir diferenças interpretativas ou incumprimentos, litigância. Os mercados têm um enquadramento institucional (uma sociedade politicamente organizada, um sistema de justiça que pode prolongar os tempos de litigância, por exemplo). A actividade económica tem lugar no seio de uma sociedade, cujas regras influenciam quer os mercados quer os contractos (Furubotn e Richter, 1997: 43-48). Não se pode compreender nada disto com uma concepção que ignora o espaço.

Até por isso, ignorar o espaço vai de par com a incompreensão da incompletude como característica básica da nossa condição de seres humanos. Que é também incompreensão da nossa condição epistemológica. Nunca sabemos tudo sobre um mundo complexo e incerto, com imensos processos naturais que não compreendemos inteiramente, cheio de outros agentes que podem não partilhar e podem até esconder informação. E transformar dados em conhecimento utilizável custa esforço e tempo. Portanto, estamos em geral em condições de informação incompleta e assimétrica (porque, em regra, nem todos os agentes têm a mesma). E, em larga medida, é nos problemas de incompletude e assimetria de informação que assentam aspectos decisivos da questão dos custos de transacção.

Esta questão coloca-nos no ponto de intersecção entre as concepções sobre as práticas sociais e concepções mais gerais acerca da estrutura da realidade. Vamos agora deixar de lado a questão do tempo e concentrar-nos na questão do espaço.

2. Agnew (2011) sugere um cruzamento entre duas concepções de espaço e duas concepções de acção humana.

A visão objectivista do espaço em Newton opõe-se à visão relacional do espaço em Leibniz. O espaço newtoniano é absoluto, é uma entidade independente dos objectos e eventos que eventualmente o ocupem, contém esses objectos e eventos, tem poderes próprios (como os que resultam das forças que operam através dele, como a atracção gravitacional ou magnética) e esses poderes são separados dos poderes dos objectos e eventos que estão e ocorrem no espaço. Já na concepção leibniziana o espaço é relacional: tudo o que interessa no espaço resulta inteiramente das relações entre os objectos e os eventos; 0 espaço existe devido às relações entre lugares, nos quais eventos e objectos estão localizados com os seus poderes próprios. 
A esta polarização entre uma concepção objectivista e uma concepção relacional do espaço vem juntar-se outra polarização entre duas concepções da acção humana. Nas concepções subjectivistas da acção humana, mesmo que se reconheça a força das circunstâncias e os condicionalismos, somos entendidos como essencialmente determinados a partir de dentro. Já as concepções objectivistas da acção humana sublinham como somos impelidos por forças que determinam ou empurram o que fazemos no mundo, sendo sempre as causas internas fracas para contrariar a maciça pressão do mundo sobre o indivíduo.

Cruzando estes dois eixos, Agnew diz, então, que as concepções subjectivistas da acção humana se conjugam com noções objectivistas do espaço (a acção humana, subjectiva, tem o espaço como o seu continente objectivo: é na realidade do espaço, e dos seus constrangimentos próprios, que encontramos o nosso caminho), enquanto as concepções objectivistas da acção humana vão de par com noções relacionais acerca do espaço (são as forças relacionais que empurram a acção humana que estruturam o espaço, porque o espaço é o resultado dessas relações).

3. Teríamos, então, uma oposição entre, por um lado, concepções subjectivistas da acção humana, articuladas com concepções objectivistas do espaço e, por outro lado, concepções objectivistas da acção humana articuladas com concepções relacionais do espaço. Ora, a verdade é que, se adoptarmos um ponto de vista institucionalista, temos de criticar essas oposições: a oposição entre subjectivismo e objectivismo é demasiado pobre para compreender aspectos importantes da acção humana (como defenderemos no ponto 4); a oposição entre uma visão objectivista e uma visão relacional do espaço ignora que, em certa medida, o que parecem relações dos humanos com o mundo físico são, afinal, e fundamentalmente, relações sociais mediadas por coisas (como defenderemos no ponto 5).

4. Vamos agora tentar mostrar que a oposição entre subjectivismo e objectivismo é demasiado pobre para compreender aspectos importantes da acção humana. Para isso, partimos dessa importante especificidade das sociedades humanas que é a existência de instituições. Uma entrada incontornável para pensar estas questões é a obra de John Searle (1995) sobre a construção da realidade social.

A distinção básica a considerar é entre factos brutos e factos institucionais. Temos um facto bruto quando a sua existência nada deve aos observadores (o pico do monte Evereste está a $\mathrm{N}$ metros de altitude). Um facto social é aquele que envolve intencionalidade colectiva: estou a tocar violino como parte da orquestra estar a tocar uma sinfonia; a orquestra a tocar a sinfonia não é um sucedâneo de uma colecção de executantes a tocar partes da peça.

Agora, os factos institucionais são um subconjunto dos factos sociais. A criação de factos institucionais envolve os mecanismos pelos quais um colectivo decide atribuir certa função a um dado tipo de objectos, quando essa função não podia decorrer apenas das características físicas (ou químicas, ou biológicas) desse objecto e tem de ser activada pela cooperação continuada entre os indivíduos desse colectivo. 
Partindo desta distinção, Searle (2006) sistematiza uma abordagem à realidade institucional como realidade especificamente humana, assente em três pilares.

Primeiro, a intencionalidade colectiva. Além da intencionalidade individual existe intencionalidade colectiva, descritível por formas como "Nós desejamos", "Nós cremos", "Nós tencionamos". A intencionalidade colectiva pode apresentar-se, nomeadamente, como acção intencional colectiva (tocar violino como parte de tocar a sinfonia). Searle define os factos sociais como qualquer facto envolvendo intencionalidade colectiva de dois ou mais agentes humanos ou animais (por exemplo, um grupo de hienas a caçar um leão).

Segundo, as funções de estatuto. Os humanos, bem como certos animais, têm a capacidade de atribuir funções a objectos. Se uma pessoa pode usar um cepo como cadeira, um grupo pode usar um tronco como banco. Aqui, a atribuição funcional é suportada por características físicas dos objectos. Os humanos, parece que em exclusividade, são capazes de atribuições funcionais para as quais as características físicas do objecto são largamente irrelevantes. Nesse caso, falamos de funções de estatuto. Por exemplo, o dinheiro, como função, não depende do suporte físico escolhido para notas ou moedas, apesar de certos critérios terem relevância prática (facilitar o transporte, dificultar a falsificação). A moeda funciona graças ao estatuto que lhe foi atribuído colectivamente pelos humanos. Em geral, factos institucionais e instituições são criados por funções de estatuto, atribuídas por actos de intencionalidade colectiva.

Terceiro, os poderes deônticos. As funções de estatuto são veículo de poder na sociedade. Aceitando funções de estatuto aceitamos um conjunto de normas que dizem respeito ao que é obrigatório, proibido ou permitido. Ficamos, desse modo, imersos numa rede de poderes deônticos. Por exemplo, a propriedade, ou o casamento, dão-me específicos direitos e deveres.

Ora, defende Searle, as formas especificamente humanas de sociedade resultam desta combinação de funções de estatuto, poderes deônticos e razões para agir independentes de desejos - combinação assente na intencionalidade colectiva. Falamos, então, de instituições.

Isto interessa-nos aqui para dizer que a realidade institucional, se aceitarmos este tipo de abordagem, perturba aquela oposição entre concepções subjectivistas e objectivistas da acção humana. É que os factos institucionais não são objectivos, no sentido de não serem forças exteriores à própria acção humana, nem são subjectivos, na medida em que não são determinados pela interioridade do indivíduo. Tomemos um exemplo.

O pedaço de papel que tenho na carteira é uma nota de dez euros. Esse facto não é um facto natural; é um facto institucional, que depende do que muitas pessoas dizem e fazem, tanto no uso dessa nota, como na sua produção. Nesse sentido, não é um facto com força exterior à nossa própria acção como seres humanos. Não é um facto bruto. Mas, por outro lado, eu não tenho o poder pessoal de desfazer esse facto. Se eu não quiser reconhecer aquela nota como uma nota, aquele papel não deixa de ser uma nota por causa do meu querer ou do meu agir individual. Até posso fazer certas coisas como se o papel tivesse deixado de ser uma nota: posso deitá-la para o lixo, como se não valesse 
nada - mas, mesmo assim, esse é um poder ilusório, porque eu perdi mesmo dez euros por ter deitado esse papel para o lixo. Esta não é uma região do mundo onde a minha subjectividade, agindo individualmente, tenha mais importância do que teria a minha ignorância sobre a altitude do pico mais alto do Evereste. Ora, sendo os factos institucionais dependentes do que nós fazemos colectivamente (podemos acabar com o sistema monetário que faz com que aquele pedaço de papel seja uma nota de dez euros, se colectivamente agirmos nesse sentido), mas não modificáveis pelo que nós fazemos individualmente, poderemos dizer que a oposição objectivo/subjectivo não serve para explicar a realidade institucional. Num certo sentido, sim, o colectivo pode impor-nos uma certa objectividade, ditando normas e esquemas de funcionamento que nos aparecem como exterioridade - mas nós fazemos parte desse colectivo e podemos, a partir da nossa subjectividade e mobilizando outras subjectividades, modificar as instituições. Nós podemos envolver-nos em trabalhos de construção institucional, modificando essa objectividade quase-dura das instituições existentes (porque é, efectivamente, difícil mudar no tempo das nossas vidas algo de substancial nas instituições sociais), mas não temos meio de impor a nossa subjectividade individual ao ambiente institucional que habitamos. Assim, numa perspectiva institucionalista, a oposição objectividade/subjectividade acerca da acção humana revela-se fraca.

5. Vamos agora tentar perturbar a oposição entre uma visão objectivista e uma visão relacional do espaço, mostrando, ainda de um ponto de vista institucionalista, que certos fenómenos, embora pareçam relações dos humanos com o mundo físico são, afinal, e fundamentalmente, também relações sociais mediadas por coisas. Ou seja: é problemático encarar o espaço como uma realidade física separável da realidade social; desde que compreendamos o mundo humano como um mundo de instituições, entendemos que parte do que encaramos como interacção com o mundo físico é, afinal, também um mundo de relações sociais.

Vejamos o exemplo da propriedade. A propriedade já foi encarada como a mera posse física de alguma coisa. A posse de um terreno implicava a capacidade para o controlar e impedir outros de nele exercerem qualquer actividade que o possuidor não desejasse. Entretanto, num quadro institucional em que há protecção legal de certos valores, posso ser proprietário de bens que não controlo fisicamente: até de bens que nunca vi.

Num artigo de 1960, Ronald Coase, falando de factores de produção de um modo que pode ser alargado a outras coisas materiais no mundo, apresenta de forma muito interessante a questão. Escreve Coase que a propriedade não é a posse física de alguma coisa, mas a detenção de certos direitos, o direito de levar a cabo certas acções constantes de uma lista restrita. E essa lista é susceptível de modificação, mesmo não mudando nada no aspecto físico da questão. E exemplifica: o proprietário de uma porção de terreno tem direitos limitados sobre o mesmo; eventualmente, nem sequer lhe será permitido levar parte da terra para outro lado (no caso de serem proibidas escavações naquele local); em princípio, é-lhe permitido proibir outras pessoas de lá entrar, mas nem sempre será o 
caso: em certos contextos ser-lhe-ão impostos direitos de passagem; certos usos do terreno serão interditos: por exemplo construir edifícios em terreno agrícola, ou certas plantações em certas áreas. Esta lista de direitos, tenha base legal ou tradicional, mostrará, em qualquer caso, como a propriedade não se explica pela posse física de uma coisa, mas por uma certa construção de relações sociais.

Harold Demsetz também elaborou sobre este ponto, afirmando que no mundo de Robinson Crusoe não há direitos de propriedade, que são consentimentos dos outros para agir de certas maneiras e proibições de agir de outras maneiras (Demsetz, 1967: 347). As transacções no mercado não são meras transacções de coisas físicas ou serviços, mas transacções de direitos. Os preços e as quantidades envolvidas nas trocas não são factos brutos da natureza, na medida em que dependem dos direitos associados - e os direitos de propriedade são mediadores de relações complexas entre pessoas e coisas. Direitos de propriedade podem permitir a uma pessoa prejudicar ou beneficiar outras - e uma certa lista de acções permitidas e proibidas como forma de um certo direito de propriedade pode ter um aspecto estranho. Por exemplo, uma pessoa pode ser proprietária de um bem e mesmo assim ser proibida de o vender abaixo de um certo preço - e, ao mesmo tempo, ser-lhe permitido disparar contra outra pessoa para evitar uma invasão de propriedade. Ao mesmo tempo, o que os direitos de propriedade efectivamente são vai depender largamente da relação entre o mundo institucional e outros aspectos materiais e imateriais do contexto. Por exemplo, numa pequena cidade americana há uma intensa protecção legal e tradicional de um sem número de aspectos dos direitos de propriedade, enquanto os direitos de propriedade na Beirute dos anos 1980 estavam quase inteiramente na mão de quem se apoderasse deles pela força (North, 1990: 33-34).

6. As observações anteriores, guiadas pelo ponto de vista institucionalista, sugerem que a oposição entre as perspectivas objectivista e relacional acerca do espaço como infra-estrutura da realidade, bem como a oposição entre objectivismo e subjectivismo acerca da acção humana, são oposições cujo dualismo parece insuficiente para compreender o real. Face a estas questões, precisamos de romper quer com a oposição entre ser objectivo e ser relacional, quer com a oposição entre ser sujeito e ser objecto. É esse trabalho que faz, precisamente, a Teoria Actor-Rede.

Resultante principalmente da obra de Bruno Latour, a Teoria Actor-Rede (cf., para uma apresentação global, Latour, 2005) é uma filosofia da materialidade relacional, de um mundo em rede onde a acção colectiva é acção de todo o tipo de forças e não apenas do que costumamos chamar "actores" (como em "actores sociais"). Recusando as oposições dualistas entre sociedade e natureza, humano e não humano, conteúdo e contexto, intencional e não intencional, Latour concebe o mundo a ser feito por actantes: nem "actores" (porque também estamos a falar de átomos, comboios, numerais), nem "objectos" (porque os objectos também têm agência, porque objectos inanimados também são responsáveis pela construção de factos). Cada entidade, humana ou não humana, natural ou artificial, é uma força - e todas as entidades no mundo estão onto- 
logicamente no mesmo pé. Enquanto actantes, todas essas entidades são as suas relações; cada uma reforça outras e resiste a outras, estabelecendo e rompendo relações, construindo alianças, negociando, modificando neste ou naquele sentido a grande rede do mundo material, constantemente deformando e reconstituindo identidades.

Latour insiste em que nada nesta perspectiva é construtivismo social: não se trata de que a sociedade dos humanos molde o mundo, porque o mundo resiste, a materialidade tem as suas próprias forças. Tão-pouco se trata de relativismo: não conseguimos fazer tudo o que queremos do mundo (contra Heidegger, o homem não é sequer o pastor do ser). Nem tudo o que fazemos no mundo é o que conscientemente queríamos fazer. O actor-rede não é a fonte da acção, mas está imerso em acção que o ultrapassa. Qualquer coisa que modifique o estado de coisas, fazendo uma diferença, é um actante: mas muita acção não foi intencionada por ninguém. É preciso mobilizar a materialidade do mundo para nele conseguir fazer alguma coisa. Até para concretizar um evento simples como organizar uma palestra numa sala com público, imensas entidades no mundo material têm de ser mobilizadas. A intersubjectividade precisa da interobjectividade: qualquer coisa que se faça no mundo passa por mobilizar, implicar actantes não humanos. Assim, trabalhar com a distinção entre Natureza e Sociedade é desinteressante, ou mesmo contraproducente: só grandes coligações de "actores sociais" e de "objectos não sociais" conseguem transportar forças das causas para os efeitos, concatenando longas séries de mediadores capazes de produzir alguma transformação. Por isso a "acção colectiva" só se produz num mundo comum onde o humano e o intencional não têm a prioridade, antes pelo contrário, são o menos resistente ao permanente embate das forças. E só entendendo isso nos habilitamos a compreender a proliferação ontológica dos nossos dias, onde os híbridos destroem fronteiras, entre a máquina e o orgânico, entre o natural e o artificial, entre o humano e o não humano.

$\mathrm{Na}$ Teoria Actor-Rede, tal como apresentada por Latour, as oposições subjectivo/objectivo e objectivo/relacional são desactualizadas pela supressão das distinções ontológicas entre entidades e forças e entre sujeitos e objectos. As entidades só são as forças que exercem e sofrem (e exercer ou sofrer força é ser entidade) e os sujeitos só são agentes em coligação com os objectos (e os objectos são agentes). Pensando a questão do espaço nesta perspectiva, o espaço é uma construção, mas não é uma construção subjectiva, nem puramente humana. O espaço é uma construção cooperativa entre a natureza e os agentes em sociedade. Metafisicamente (quer dizer, sem sermos capazes de conceber um teste empírico para esta hipótese) podemos conceber o espaço como o ser da totalidade do que existe em função do modo de existência dos actantes. Isto implicaria reconhecer que o espaço existe para lá da acção humana, mas que a acção humana pode modificar o espaço, reconfigurá-lo. Talvez seja pouco prático pensar nisso à escala do universo, essa imensidão onde a presença humana é vastamente irrelevante.

Poderá o pensamento geográfico acolher um programa de investigação que transforme esta hipótese metafísica numa hipótese científica? Tratar-se-ia, então, de compreender se a acção dos humanos a (re)construir instituições pode, nesse passo, fazer 
deles (de nós) também agentes de reconstrução do próprio espaço. Há espaços mais densamente ocupados por instituições e há espaços mais vazios de instituições: pode a expansão das instituições no espaço, a conquista institucional do espaço, transformar o próprio espaço? Pode o espaço entre instituições (o espaço ainda virgem de instituições) ser ocupado por instituições? E pode isso modificar o próprio espaço, distorcer o espaço, reconfigurar o espaço?

\section{BIBLIOGRAFIA}

Agnew, J. A. (2011). Space and place. In J. A. Agnew, \& D. N. Livingstone (Eds.), The SAGE handbook of geographical knowledge (316-330). Londres: Sage.

Coase, R. H. (1960). The problem of social cost. Journal of Law and Economics, III, 1-44.

Demsetz, H. (1967). Toward a theory of property rights. The American Economic Review, 57, 347-359.

Furubotn, E. G., \& Richter, R. (1997). Institutions and Economic Theory. The Contribution of the New Institutional Economics. Ann Arbor, University of Michigan Press.
Latour, B. (2005). Reassembling the Social: An Introduction to Actor-Network-Theory. Oxford: Oxford University Press.

North, D. C. (1990). Institutions, Institutional Change and Economic Performance. Cambridge: Cambridge University Press.

Searle, J. R. (1995). The Construction of Social Reality. New York: The Penguin Press.

Searle, J. R. (2006). Social ontology: some basic principles. Anthropological Theory, 6, 12-29. 